\section{How can Customer Analytics Capabilities Influence Organizational Performance? A moderated mediation analysis}

\author{
Alamir Costa Louro ${ }^{1,+}$ \\ ${ }^{1}$ Universidade Federal do Espirito Santo, Vitória, ES, Brazil \\ Marcelo Moll Brandão ${ }^{2, \Omega(1)}$ \\ ${ }^{2}$ Universidade Federal do Espirito Santo, Vitória, ES, Brazil \\ Jurij Jaklič ${ }^{3, ¥}$ (D) \\ ${ }^{3}$ University of Ljubljana, Ljubljana, Slovenia \\ Arthur Sarcinelli 4,*(1) \\ ${ }^{4}$ Universidade Federal do Espirito Santo, Vitória, ES, Brazil
}

\section{ABSTRACT}

A theoretical model is proposed to test the relationship between Customer Analytics Capabilities and Market Orientation with Organizational Performance, encompassing Marketing Capabilities as a mediator mechanism moderated by Environmental Dynamism. Its contribution lies in the test of this mediation in different types of industries in Brazil, by using SmartPLS software for structural equation modeling (SEM) and IBM SPSS with PROCESS macro for more in-depth insights. The results confirm the moderated mediation but show different behaviors about the direct effect for Customer Analytics Capabilities and Market Orientation, which suggest future studies. The study supports a better understanding of some of the diverse capabilities types and proposes an adaptive new one, Customer Analytics Capabilities, which is the final insertion of the Analytics concept in Marketing and Strategy disciplines.

Keywords: Customer Analytics Capabilities. Market Orientation. Marketing Capabilities.

\section{INTRODUCTION}

The Marketing discipline increases attention in emerging revolutionary technologies and its effects on the relationship between market knowledge learning and organizational performance, in particular using the capabilities literature (Chang, Park, \& Chaiy, 2010; Wamba et al., 2017). In this already emerged scenario, the organizations need to learn or even anchor themselves in the decision-making based on rationality, and ultimately compete by collecting, analyzing, and acting data-driven (Davenport, 2006).

Data-driven decision-making organizations will be working in the interface, between econometrics, psychometrics, statistics and computer science, as exemplified in the historical revision of Marketing discipline methods by Wedel and Kannan (2016). Additionally, the Marketing discipline is the first choice for data-driven decision-making, easing organizations in markets dynamics, for example, in customer segmentation, in customer behavior analysis for online campaigns or cross-selling recommendation systems (Provost \& Fawcett, 2013).
Corresponding author:

${ }^{\dagger}$ Universidade Federal do Espirito Santo, Vitória, ES, Brazil

E-mail: alamirlouro@gmail.com

${ }^{\Omega}$ Universidade Federal do Espirito

Santo, Vitória, ES, Brazil

E-mail: mollmkt@gmail.com

${ }^{¥}$ University of Ljubljana, Ljubljana,

Slovenia

E-mail: jurij.jaklic@ef.uni-li.si

${ }^{*}$ Universidade Federal do Espirito Santo, Vitória, ES, Brazil

E-mail: thearthursarcinelli@gmail.com

Received: 05/06/2018.

Revised: 08/01/2018.

Accepted: 09/12/2018.

Published Online: 05/29/2019.

DOI: http://dx.doi.org/10.15728/bbr.2019.16.4.4 
In Wade and Hulland (2004), we already find the tendency of the Information Systems, Dynamic Capabilities, and Resource Based View (RBV) literature, supporting themselves to explain the latent phenomenon of the technologies that bring the creation and improvement of Organizational Performance. For example, the information volume conveyed by "Big Data", or related to the connectivity of the customer by the mobiles and the Internet of Things (IoT). Another example is the innovative use of information already available within the organizations or even within some digital media by data mining. These phenomena are recent, complex and hugely debated (Wamba et al., 2017), but little explored empirically (Germann, Lilien, Fiedler, \& Kraus, 2014).

The advanced analysis with customer emphasis, nominated by the present work as Customer Analytics, helps transform the organization's internal or external data, structured or not, in strategic information. It demands some in-depth Marketing modeling techniques knowledge for prediction of the market's response, and optimization of marketing-mix and personalization for the customers (Wedel \& Kannan, 2016). With this contemporary phenomenon and utilizing traditional literature of Market Orientation (MO), we expect to expand the knowledge on Marketing Capabilities (MC) mechanism. This approach is similar to Kozlenkova, Samaha and Palmatier (2014) that also included in the Dynamic Capabilities framework the concepts of performance, $\mathrm{MO}$, and innovation, encompassing new technological phenomenon.

The most prominent contribution of the present work is found in the establishment of the association between the concepts of Customer Analytics Capabilities (CAC) and MO mediated by $\mathrm{MC}$ to reach Organizational Performance in different types of industries and environmental dynamism. Additionally, another underpinning contribution is to assist with a more robust knowledge about the diverse sorts of Capabilities in the extant literature, lastly, defining a proper, Customer Analytics Capabilities. This Capability can be found in organizations that continually feel and act upon the emerging trends and technologies in their markets; these organizations are more prone to listen to potential customer opportunities.

These elements, already known in the extant literature, market knowledge, MCs, and Customer Analytics together are fundamental to the present work edification as a theoretical model that complements the building blocks found in works such as Morgan, Vorhies and Mason (2009), Day (2011) and Morgan (2012). How Market knowledge is learned in the already emerged scenario justify the present work.

Synthetically, the paper understands that the market knowledge is utilized by the MCs mechanism to produce performance. Both MO and CAC help in this learning process, but these mediated effects are dependent on Environmental Dynamism because there is different adaptation needs to organizational environment. This approach is inspired in Kohli and Jaworski (1990), which talks about a particular vision of market information based on Market Orientation theory, but goes ahead with the new technologies advent and the possibility of testing MCs mechanism.

\section{THEORETICAL REVIEW}

There is a high number and variety of studies that relate Dynamic Capabilities and Marketing (Barrales-Molina, Martínez-López, \& Gázquez-Abad, 2014; Braganza, Brooks, Nepelski, Ali, \& Moro, 2017; Felipe, Roldán, \& Leal-Rodríguez, 2016; Wamba et al., 2017). In the national literature, Dynamic Capabilities, Marketing Capabilities, and Organizational Performance relationships show recent interest too (Takahashi, Bulgacov, Semprebon, \& Giacomini, 2017).

The review by Barrales-Molina, Martínez-López, and Gázquez-Abad (2014) shows the diverse point of views, which turned out hard to synthesize and compare because there is a "wide range of Marketing resources, capabilities and, processes" (p.2) that hinder the 
BBR

16,4

connection and integration of these elements into a common framework. Despite this initial difficulty, the present work assumes that there are specific Marketing Capabilities (MC) that are different from Operational Capabilities (Morgan, 2012) and are different from learning/absorptive capabilities (Pavlou \& Sawy, 2010).

Customer orientation is one of the three pillars of the Market Orientation (MO) Theory, and the other two are coordinated marketing and profitability (Kohli \& Jaworski, 1990). These authors highlighted MO as a competitive advantage source, but of hard engendering. For these authors, MO "involves obtaining information from customers about their needs and preferences" (p.3), not only the current but the future ones too, introducing the Market Intelligence concept, a concept that transcends the organizations' limits.

Morgan, Vorhies, and Mason (2009) confirm the importance of MO used in conjunction with DCs, these authors suggest the integration between market knowledge and Marketing Capabilities as a way to comprehend the Organizational Performance (OP). Therefore these authors' approach is similar to the present work. Additionally, their study measured OP objectively and subjectively. Performance is a multidimensional concept, whose attributes change throughout time, as well as among stakeholders and organizations (Matitz \& Bulgacov, 2011). Morgan, Vorhies, and Mason (2009), effectuated performance measurement in a scenario which involved the MO, DC, and MC. Then this approach it's not a new topic, but performance is still a complex construct and is not the focus of the present work. Due to the difficulty of the gathering objective performance results in a crossindustry survey, the present work only measures performance in a subjective way.

Germann, Lilien, Fiedler and Kraus (2014) discuss the underspend of Customer Analytics technologies on retailing despite the high potential use in this industry. These authors postulate the industries attributes that are more likely to benefit themselves, like the existence of plenty of customer data, adequate technology for specific customers problems, and the possibilities of these technologies to support repetitive decisions. Speaking on analytics as a general area, like Business Analytics, Customer Analytics and Big Data Analytics, other industries have also been studied in a specialized manner. For example, the health-care (Wang \& Hajli, 2017), banking (Persson \& Ryals, 2014) and the Information Technology industries (Braganza, Brooks, Nepelski, Ali, \& Moro, 2017). Otherwise, the type of industry interferes with the Analytics usage (Wamba et al., 2017).

The Customer Analytics Capabilities (CAC) is an Adaptive Capability defined by Day (2011). This author also differentiate it from some other Capabilities types discussing the Marketing Capabilities Gap, he criticizes the current RBV literature, and even the current DC literature, as less dynamic theories than the environment demands, suggesting the existence of the Adaptive Capabilities. Regardless of the adopted terminology, dynamic or adaptive, for the present work, CAC explore better the information sources, and reflects the customer information quality; a team with specific expertise explores it after a learning process, similar to the point of view of Day (2011). This second order construct has its three reflective constructs detailed next.

\subsection{CUSTOMER INFORMATION QUALITY}

The Customer Relationship Management (CRM) concept is giving space to a more open perspective, which recognizes new Capabilities enabled by revolutionary emerging technologies, such as the social media usage to gather customer information (Trainor, 2012). On this enlarging context, to exemplify, Netflix analyzes millions of their viewers' data in real time, helping to determine if a new pilot movie will become a successful option (Xu, Frankwick, \& Ramirez, 2016). These authors still say that Big Data Analytics disrupts other daily basis scenarios, perceived in the present work as only a revolutionary emerging technology, not as a capability because it's essentially the same predictive known method 
with hundreds of variables. In addition to that, there are other revolutionary emerging technologies that deal with customer data; it is necessary to highlight the ubiquity of the IoT described as the "new technology paradigm envisioned as a global network of machines and devices capable of interacting with each other" (Lee \& Lee, 2015, p. 431). These authors affirm that IoT, devices or sensors, generate enormous amounts of customer data and can transmit it directly, without a CRM system, to business intelligence or analytics tools for humans, or not, to make decisions.

The systems quality and customer information quality were constructs measured by Gorla, Somers and Wong (2010) which found a relationship between the systems quality and customer information quality; conversely, they also measured a positive relationship between the information quality and organizations impact. In addition to this relationship between systems quality and information quality, the former is not regarded on the present study because the research respondents are professionals of more specific areas which may not have a complete vision on the quality of the system. Nonetheless, they need to know the customer information quality which they work with directly. This information may come from Big Data, IoT, or from common spreadsheets or also from external data as social media.

\subsection{TEAM EXPERTISE}

Some updated quantitative studies provide empiric evidence that confirms the role developed by the organizational capability to generate dynamism from their innovation team to reach competitive advantage (Barrales-Molina, Martínez-López, \& GázquezAbad, 2014; Singhal \& Singhal, 2012). A typical case was executed with Chinese senior executives; this case identified that administrating the knowledge capability of individuals can provide exchange and integration for the whole team knowledge (Tseng \& Lee, 2014). Moreover, this improves the organizational financial performance because it includes return on investments and high profitability which allows the development of products and services in a much faster way and with better quality.

The analytical expertise proposed by the present work has an intrinsic relationship with Day (2011) as a response to "Organizational rigidities"(p. 184) like structural-functional insularity and lagging reactions to the market. In addition, the author highlights as solutions, market learning in an immersive and vigilant way. Analytical expertise responds to market stimuli with an open approach to potential customer needs. Another highlighted characteristic by the same author is the experimental mentality, in addition to the action driven by quantitative evidence (Davenport, 2006).

\subsection{CUSTOMER KNOWLEDGE ABSORPTION}

Customer Analytics technologies can help in the absorption of the so-called "external competencies" or "market knowledge" (Barrales-Molina, Martínez-López, \& GázquezAbad, 2014). Davenport (2006) exemplifies the knowledge absorption saying that the organizations may spend many years accumulating data in different approaches to have enough customer knowledge to analyze a marketing campaign in a trusting and efficient way. This market knowledge is all the information that the organization has about the customer and their needs in different situations and various moments; past, present and future (Cooke \& Zubcsek, 2017). CAC as an Adaptive Marketing Capabilities (Day, 2011) has a construct that responds to the speed of acceleration of the market and the complexity with a more external and exploratory absorptive capability. The customer knowledge absorption is a capability with the improvement of vigilant market learning, experimentation and, openness (Day, 2011). 
BBR

16,4

\section{MODEL AND HYPOTHESIS}

The constructs described previously and the hypothesis that are explained next, resulted in the theoretical model presented in Figure 1.

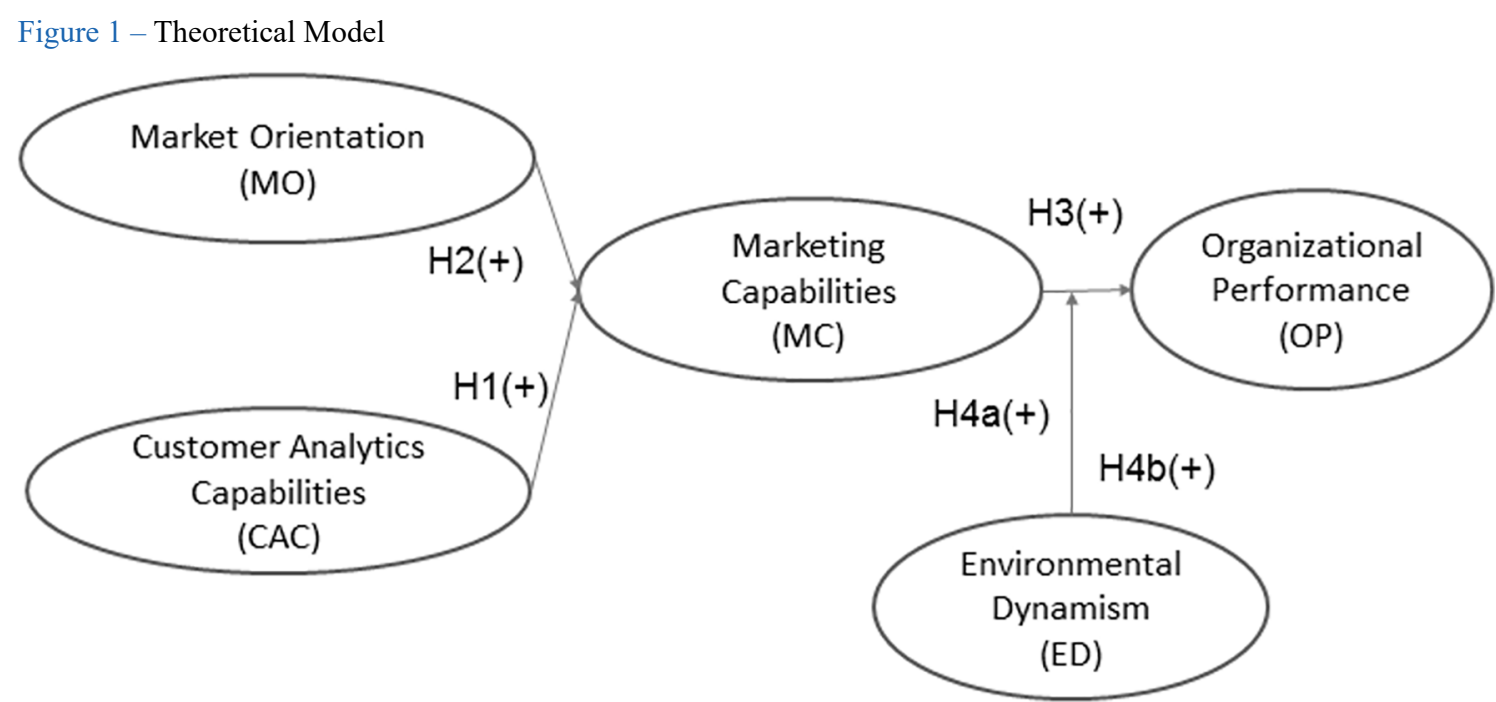

Source: Prepared by the authors (2018)

The customer knowledge absorption is a fundamental point of connection between the constructs in this paper. The ways of absorption and the knowledge nature may be diverse, from CRMs, digital media, new revolutionary technologies, etc. As an example, CRM technologies allow the organizations to formulate more appropriate Marketing strategies and execute specific Marketing actions faster and more efficiently (Chang, Park, \& Chaiy, 2010). These systems offer support to the frontline and better access to customer data (Chen \& Popovich, 2003). Notwithstanding, there is a suggestion that "the effectiveness of the CRM activities depends on how CRM is integrated with the firm's existing processes and preexisting capabilities" (Boulding, Staelin, Ehret, \& Johnston, 2005, p. 158). In brief, $\mathrm{CAC}$, as an adaptive marketing capability, depends on preexisting marketing capabilities to improve performance; this is the reason to test the mediation. However, we give better details next.

CAC, as a cross-functional analytics effort, is based on specific organizational teams, normally from the areas of IT, innovation, R\&D, marketing research or others (Wedel \& Kannan, 2016). These teams' projects cover many possibilities from the use of customer data in a rudimentary way such as using spreadsheets with purchase data, to the use of elaborate quantitative methods with data science, artificial intelligence, machine learning support, passing through business Intelligence (Wedel \& Kannan, 2016).

The CAC team problem-solving process involves quantitative evidence (experimentation with calculations, numerical analysis, etc.), sometimes as an organizational/team policy (Davenport, 2006). This process provides customer information or market knowledge acting in a cross-functional way in the organization (Wedel \& Kannan, 2016).

In addition to this analytical expertise, the CAC team has technological expertise (knowledge in programming, data engineering and technological tendencies) and business expertise (understand organization plans, is immersed in the observation of the organization's business environment to interpret business problems or customer's necessities) (Davenport, 2006).

This team needs to successfully gather and integrate information about customers from different data sources, sometimes, by combining customers' data transaction with external data (Cooke \& Zubcsek, 2017). This process creates a culture of greater importance to 
customer information about accuracy, usefulness, timely provision (Popovič, Hackney, Coelho, \& Jaklič, 2012).

The CAC team executes effective routines to identify, value and finally import/assimilate/ transform this new customer information, usually to improve new products/services or insights, it is a higher level of strategic process (Pavlou \& Sawy, 2013) that reconfigures other capabilities and resources. The assumption here is that when CAC grows, the team expertise, the customer information quality, and the absorption process grows, but it cannot grow without other capabilities, and the present work tests in specific the Marketing capabilities.

The dependence of some Capabilities to others is vital to understand the diverse Capabilities relationships. For example, CRM systems are defined as enablers to MCs (Barrales-Molina, Martínez-López, \& Gázquez-Abad, 2014). Additionally, they say that these systems and other technologies, termed as CAC here in a broader meaning, uphold the market's knowledge absorption. These capabilities dependence suggests the declaration of the first hypothesis:

H1. CAC has a direct positive effect on Marketing Capabilities.

From an extensive bibliographic revision, the literature confirms a strong relationship between Market Orientation (MO) and MCs (Barrales-Molina, Martínez-López, \& Gázquez-Abad, 2014). In their empirical study, Morgan, Vorhies and Mason (2009) state that $\mathrm{MO}$ has a liberating effect over the MCs, which make the organization more dynamic. The following hypothesis is declared using the argument from previous authors:

H2. Market Orientation has a direct positive effect on Marketing Capabilities.

Marketing literature is concerned with the relationship between organizational Marketing and performance constructs using Dynamic Capabilities (Morgan, 2012; Kozlenkova, Samaha, \& Palmatier, 2014) including the term MC. The following hypothesis is declared to confirm the literature result:

\section{H3. The Marketing Capabilities have a direct positive effect on Organizational Performance.}

Market Orientation (MO) is significantly related to organizational performance while other Marketing Capabilities (MC) interacts with MO (Morgan, Vorhies, \& Mason, 2009), meaning that $\mathrm{MC}$ needs to be beside the $\mathrm{MO}$ to boost performance. These authors have not tested the MC mediation role, but similar to the present work, these authors use MO and $\mathrm{MC}$ together to a market information processing vision, originated in Kohli and Jaworski's (1990) work to explain performance.

Trainor, Andzulis, Rapp and Agnihotri (2014) did not find direct relationship evidence between CRM technology use with social media and performance. These authors say that this discovery is consistent with the extant IT literature, which suggests that the technology alone is not enough to obtain performance improvement, instead, social media technologies only facilitate other capabilities. From the literature, the lack of consensus on the role of MC between MO, technology, and Performance was chosen to test the mediation of both separate exogenous constructs.

According to Jayachandran, Sharma, Kaufman and Raman (2005), the environmental dynamism can motivate different information exchange between organizations because the customer's relationship learning can be a critical factor in environments with high dynamism, given that the fast moves in customer needs and technological changes may complicate the customer's loyalty. There is a prominent gap between increasing environmental demand and $\mathrm{MC}$ in scenarios of high environment dynamism, and Adaptive Capabilities are the solution to minimize this gap (Day, 2011). The solution comes from the deep market insights of organizations that have $\mathrm{MO}$ and $\mathrm{CAC}$, the outside-in exploratory learning capabilities. 
H4a. Marketing Capabilities have a mediating role between the MO and Organizational Performance, and this effect is higher when moderated by Environmental Dynamism.

H4b. Marketing Capabilities have a mediating role between the CAC and Organizational Performance, and this effect is higher when moderated by Environmental Dynamism.

\section{METHODOLOGICAL ASPECTS AND CONSTRUCTS OP- ERATIONALIZATION}

The phenomenon of the association between technology and performance has been studied by diverse disciplines and researchers (Chuang \& Lin, 2017; Popovič, Hackney, Coelho, \& Jaklič, 2014). Specifically in Marketing and with the quantitative approach (Germann et al., 2014; Trainor et al., 2014) and additionally using the Capabilities literature (Chang, Park, \& Chaiy, 2010; Wamba et al., 2017). The empirical testing of the theoretical hypothesis was conducted using structural equation modeling (SEM). According to Hair, Black, Babin, Anderson and Tatham (2009) the characteristic of the sample with nonnormal data added to the fact that the model has five latent variables, and therefore several interrelated dependency relations led to the use of SEM. In this context, we chose SmartPLS software (version 3.2.4), which provides the statistical method of the Partial Least Squares (PLS).

Conservatively, conducting a statistical power test at $95 \%$, and assuming an $\mathrm{R}$ square of $25 \%$, the software Gpower determines, for a significance of $1 \%$, the size of the sample as 179 respondents. The statistical test chosen tries to maximize the multiple regressions $\mathrm{R}$ square adding new predictors to the solution, $\mathrm{f}^{2}$, (Faul, Erdfelder, Lang, \& Buchner, 2007).

The CAC construct scale creation was necessary due to the inexistence of a similar scale to measure the phenomenon with the present work focus. CAC is an Adaptive Capability, which uses customer information learned from market knowledge. CAC cannot be confused with the existing Business Analytics constructs, which usually deal with greater technological detail (Rapp, Trainor, \& Agnihotri, 2010; Wamba et al., 2017).

The first-order CAC constructs are all new. Customer information Quality is an adaptation from Chuang and Lin's (2013) scale. Thus, Team Expertise has three dimensions: (i) Analytical that is inspired in Popovič et al. (2012) and Day (2011); (ii) Technological and (iii) Business, both inspired in Kim, Shin, and Kwon (2012). Finally, Customer knowledge absorption is an adaptation inspired in Pavlou and Sawy (2013) and Pavlou and Sawy's (2010) scales and Day (2011).

In a preliminary version, the CAC construct had four first-order constructs; the Analytical Culture construct that was transformed on Team Analytical Expertise. This suggestion came from the face/content validity process that followed adapted steps from MacKenzie, Podsakoff, and Podsakoff (2011). This process was performed using a googledocs form sent and answered only by experts, in a total of four Ph.Ds. and four Ph.Ds. candidates. They associated each item from the new CAC scale, presented randomly, with the respective construct dimension to validate if the item originally thought makes sense.

The references for the other constructs are all based on known Marketing works. Marketing Orientation is the reproduction of Narver and Slater's (1990) scale, Marketing Capabilities reproduction of Song, Benedetto and Nason's (2007) scale, Organizational Performance reproduction of Jaworski and Kohli's (1993) scale and, Environmental Dynamism the reproduction of Jayachandran's et al. (2005) scale.

After the scale development, a two-stage pre-test process was performed to evaluate the quality of the 54 items in the questionnaire. On the first pre-test, the questionnaire was delivered personally to two experienced professionals, one with an IT manager profile and 
the other with a Business Intelligence Analyst profile. First and foremost, they evaluated the survey needed time. Secondly, they analyzed any ambiguity or even misunderstanding or if the items were hard to answer. After completing the first phase, the questionnaire was sent to two academics with analytics background, a master, and a Ph.D. candidate, leading to changes in the original steps by MacKenzie, Podsakoff and Podsakoff (2011).

\section{RESULTS ANALYSIS}

For hypotheses test, we used survey data from Brazilian users from Linkedin with verified profiles as Top Management; Manager/Analyst of Marketing, Product/Brand, R\&D, Innovation; and Data Analyst/Scientist, totaling $(n=179)$ records without additional treatments.

There was no missing data, but before performing any measurement model evaluation, considering that all indicators were based on a survey, a common method bias was assessed. On the present survey, all the questionnaire variables have the same source respondents, and considering there are various profiles and the Harman's one-factor was executed, following the procedures and parameters by Podsakoff, MacKenzie, Lee and Podsakoff (2003). This evaluation is just a factorial analysis, which includes all the items of all constructs of the study to determine if most of the variance can be explained by only one factor, which was not confirmed.

The PLS algorithm was executed with the default values following the guidelines by Hair, Hult, Ringle and Sarstedt (2017). All constructs have more than one variable and are reflexive. The hierarchical components are treated in two steps, and the results of the measurement model regarding the validity and reliability show Cronbach's alpha and composite reliability greater than 0.7 and AVE, greater than 0.5 , as shown in Table 01 . The external loadings of convergent validity are greater than 0.7 .

\begin{tabular}{lccc}
\multicolumn{1}{l}{ Table 1 - Construct Reliability and Validity } & \\
& \multicolumn{1}{c}{ Cronbach's Alpha } & Composite Reliability & $\begin{array}{c}\text { Average Variance Extracted } \\
\text { (AVE) }\end{array}$ \\
\hline CAC & 0.927 & 0.954 & 0.873 \\
ED & 0.761 & 0.839 & 0.515 \\
MC & 0.852 & 0.890 & 0.576 \\
MO & 0.938 & 0.946 & 0.539 \\
OP & 0.738 & 0.883 & 0.791
\end{tabular}

Source: Prepared by the authors (2018)

Also in the measurement model, we analyzed the discriminant validity by FornellLarcker's criterion, according to which the square root of the AVE must be greater than loadings of the other constructs. The cross-loading test showed no problem as per parameters by Hair et al. (2017).

Again, according to Hair et al. (2017), the first step of the structural model is to evaluate collinearity using the VIF indicator, using as a parameter lower than 5, with the highest result being 3.337. On the second step, path coefficients are evaluated using the Bootstrapping procedure with 5000 subsamples with the option "no sign changes", all coefficients are significant ( $p$-value $<0.05$ ) as shown in Table 02.

The third step is to evaluate the determination coefficient that measures the model predictive accuracy; the result was 0.726 for Marketing Capabilities and 0.414 for Organizational Performance, with adjusted values 0.723 and 0.404 respectively, which is considered near to substantial and moderate, respectively by Hair, Ringle, and Sarstedt (2011). 
BBR

16,4

Table 2 - Bootstrapping Path Coefficients

\begin{tabular}{lccccc}
\hline & $\begin{array}{c}\text { Original Sample } \\
(\mathrm{O})\end{array}$ & Sample Mean $(\mathrm{M})$ & $\begin{array}{c}\text { Standard Deviation } \\
(\text { STDEV })\end{array}$ & $\begin{array}{c}\text { T Statistics }(\mid \mathrm{O} / \\
\text { STDEV } \mid)\end{array}$ & P Values \\
\hline CAC -> MC & 0.240 & 0.236 & 0.065 & 3.685 & 0.000 \\
ED -> OP & 0.202 & 0.222 & 0.080 & 2.537 & 0.011 \\
MC -> OP & 0.544 & 0.533 & 0.080 & 6.818 & 0.000 \\
MODERATOR(ED) -> OP & 0.100 & 0.099 & 0.050 & 2.020 & 0.043 \\
MO -> MC & 0.669 & 0.675 & 0.052 & 12.865 & 0.000 \\
\hline
\end{tabular}

Source: Prepared by the authors (2018)

In step four, we seek to measure the size of the effect $f$ square $\left(f^{2}\right)$, which evaluates if any omitted constructs generate substantive impact on the endogenous constructs; the result of $\mathrm{CAC}$ and $\mathrm{MO}$ in $\mathrm{MC}$ is great, 0.933 , and $\mathrm{MC}$ in $\mathrm{OP}$ is medium 0.317.

In the fifth step, table 03 shows the predictive relevance evaluated using the Blindfolding algorithm with the default configuration, omission distance equal to 7, resulting in a $\mathrm{Q}^{2}$ that represents medium to great relevance, greater than $0.15(\mathrm{OP}=0.303)$ and $0.35(\mathrm{MC}=0.408)$ respectively, parameters by Hair et al. (2011).

Table 3 - Blindfolding

\begin{tabular}{lccc}
\hline & SSO & SSE & $\mathrm{Q}^{2}(=1-$ SSE/SSO) \\
\hline CAC & $3,580.000$ & $3,580.000$ & \\
ED & 895.000 & 895.000 & 0.408 \\
MC & $1,074.000$ & 636.241 & \\
MODERATOR(ED) & 179.000 & 179.000 & 0.303 \\
MO & $2,685.000$ & $2,685.000$ & 249.391 \\
OP & 358.000 & &
\end{tabular}

Source: Prepared by the authors (2018)

Figure 2 shows the PLS algorithm with significance and $t$ statistics. Then the three first hypothesis was confirmed, which responds to extant literature. Another test was to analyze the graphs of the Environmental Dynamism construct as a moderating effect on the relationships between Marketing Capabilities and Organizational Performance (Figure 3 left site). There is apparent moderating effect observed in the left side of Figure 3, after the Bootstrapping execution with the endogenous construct Organizational Performance (OP), the result was significant 0.042 , close to the limit of 0.05 . In summary, the analysis of SEM carried out in SmartPLS resulted in the confirmation of the four hypothesis.

Figure 2 - SmartPLS results

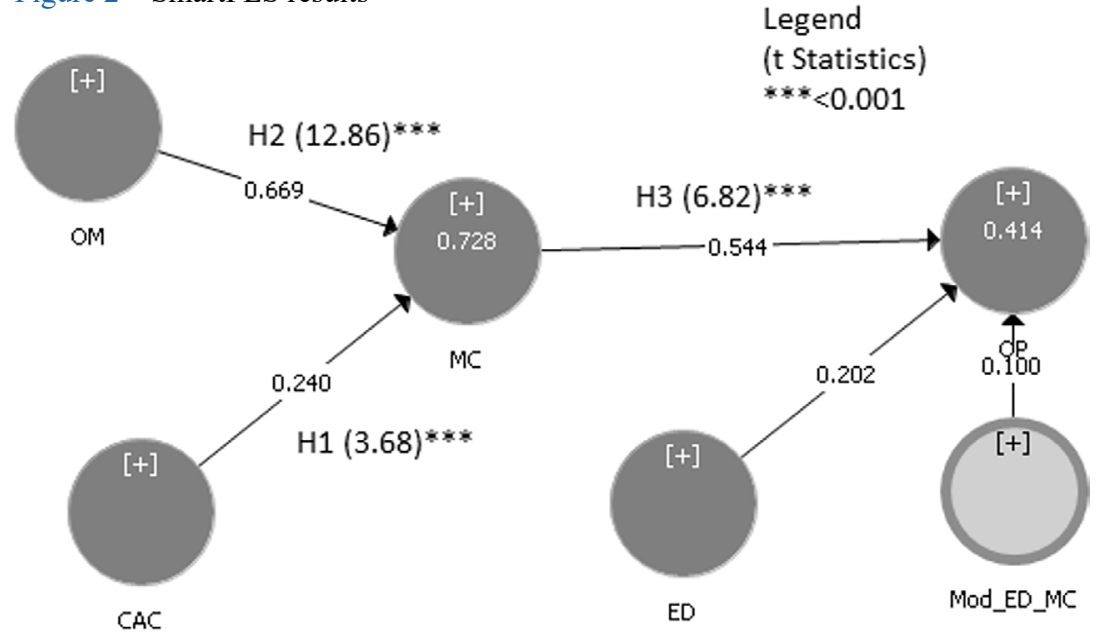

Source: Prepared by the authors (2018) 
Figure 3 shows both moderated mediation test results in PROCESS for MO (H4a) and CAC (H4b) (Figure 3 - right site). To improve the PLS analysis, we tested the moderated mediation for $\mathrm{H} 4 \mathrm{a}$ and $\mathrm{H} 4 \mathrm{~b}$ based on PROCESS Model 14, according to procedures by Hayes (2013), it showed for $\mathrm{H} 4 \mathrm{a}$ that $\mathrm{MO}>\mathrm{MC}>\mathrm{OP}$ was partially mediated and moderated by ED. The effects test was performed with 10000 samples bootstrap. In the case of H4b, the direct relationship between CAC and OP was not significant, the other relationships are significant, which demonstrates a total MC mediation and moderation by ED.

Figure 3 - SmartPLS Moderator test and PROCESS SPSS test

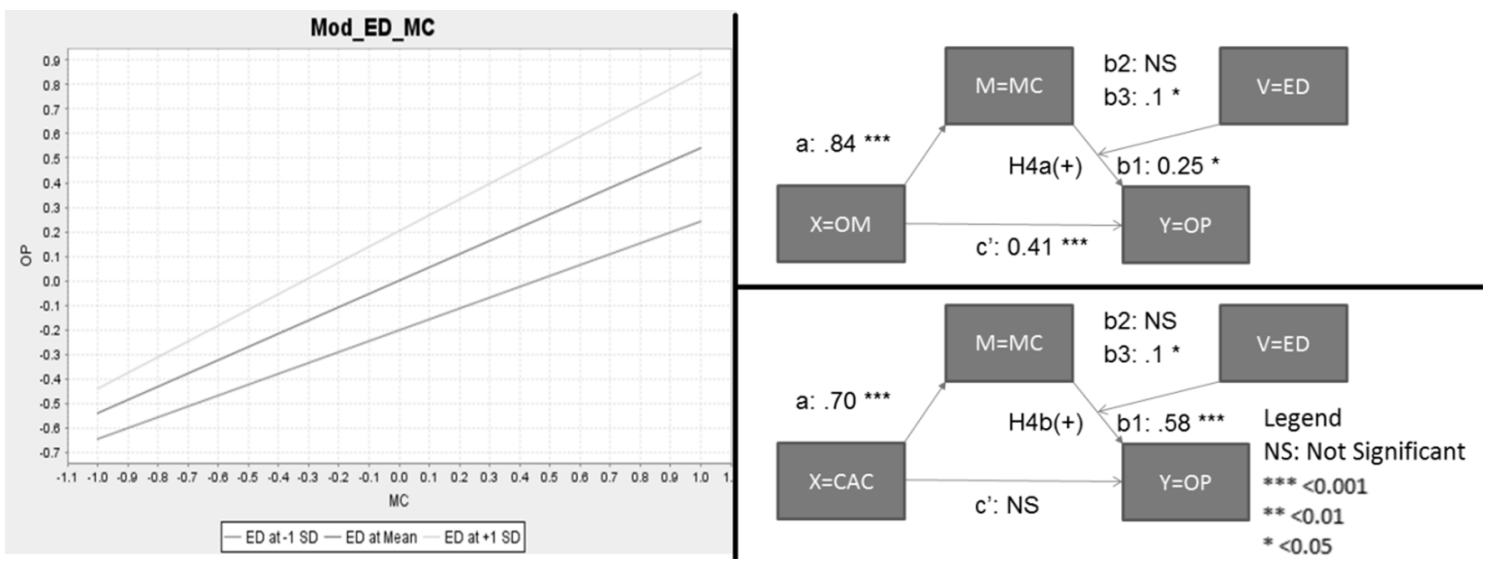

Source: Prepared by the authors (2018)

The tests of H4a showed the improvement in effect from 0.12 (-1SD not significant), 0.21 (mean) to 0.29 ( $+1 \mathrm{SD})$. Thus, the tests of $\mathrm{H} 4 \mathrm{~b}$ showed the improvement from 0.34 $(-1 \mathrm{SD}), 0.41$ (mean) to 0.48 ( $+1 \mathrm{SD}$ ) all significant. The result of $\mathrm{H} 4 \mathrm{a}$ is different from $\mathrm{H} 4 \mathrm{~b}$, but both are considered confirmed hypothesis because there is no theoretical hypothesis for the direct effect.

In summary, all hypothesis confirmation is shown in Table 04.

\begin{tabular}{lll}
\multicolumn{2}{l}{ Table 4-Research hypothesis } & Results \\
\hline Hypothesis & Description & Confirmed \\
H1 & CAC has a direct positive effect on Marketing Capabilities. & Confirmed \\
H3 & Market Orientation has a direct positive effect on Marketing Capabilities. & \\
& The Marketing Capabilities have a direct positive effect on Organizational Confirmed \\
H4a & Performance. & Marketing Capabilities have a mediating role between the MO and Organizational Confirmed \\
& Performance, and this effect is higher when moderated by Environmental & \\
H4b & Dynamism. & \\
& Marketing Capabilities have a mediating role between the CAC and Organizational Confirmed \\
& Performance, and this effect is higher when moderated by Environmental & \\
& Dynamism.
\end{tabular}

Source: Prepared by the authors (2018)

\section{CONCLUSIONS}

The tests for hypotheses $\mathrm{H} 1$ and H4b showed that CAC is dependent on Marketing Capabilities, as predicted by Barrales-Molina, Martínez-López and Gázquez-Abad (2014), when discussing about technology as an enabler when inserted in DCs framework, CAC 
BBR

16,4

uphold the market's knowledge absorption, and this mediation is the most important contribution in the present study. The moderated mediation of $\mathrm{MC}$ for CAC expands knowledge for managers and academics, in particular for managers taking for granted the boom of analytics and data science in the market.

Concerning the second hypothesis $\mathrm{H} 2$, it showed a strong relationship between $\mathrm{MO}$ and MCs confirming the empirical study by Morgan, Vorhies, and Mason (2009). However, $\mathrm{H} 4 \mathrm{a}$ showed that the moderated mediation is partial because MO can influence OP directly. In turn, hypothesis H3 also confirms the literature (Morgan, 2012; Kozlenkova, Samaha, \& Palmatier, 2014). Both $\mathrm{H} 2$ and $\mathrm{H} 3$ are important for top management concerned about customer commitment, satisfaction, and value creation.

The main test is the moderated mediation of CAC and MO to boost performance and Environmental Dynamism taking an important role maximizing the mediation, perhaps this is explained by the increased need for customer information because of rapid changes in customer needs and technological changes. The adaptive capabilities like CAC could help to minimize the marketing capabilities gap.

Regarding the H4a and H4b hypotheses, a more careful analysis is needed despite the fact that they are confirmed. The present study is limited regarding the existence of different inflection points by industry from different environmental dynamism (ED), the inflection point is the value of ED that improves the mediation. Future studies can exploit more the different behaviors of CAC and MO about the direct effect. CAC is fully mediated by marketing capabilities and can be related to others capabilities in diverse contexts.

As an academic contribution, the idea of researching the market orientation and performance, $\mathrm{H} 4 \mathrm{~b}$, is not entirely new, but the progress occurs in testing in the Brazilian context. The results on marketing capabilities seem to expand the field in national context not just replicating international studies but applying the survey to different environmental dynamisms. For management, these results suggest precaution for headhunters because not all kinds of industries or environmental dynamism requires Customer Analytics professionals.

The results also contribute to the scarce empirical literature on the adaptive capabilities, especially building a new construct, CAC, with three first-order constructs in a hierarchical component model. As for the academic interest, this approach provides a significant indication of the need for greater understanding of new emerging technologies.

Regarding the importance of Environmental dynamism, future studies could improve the present study with different countries and establish new views on this construct including a classification for diverse industries and/or organization size and/or technology dependence.

The focus of the study on organizational performance using only two subjective indicators represents another limitation of the present study; it is understood that several other indicators could be measured, such as objective and others related to customer relationship performance. Future research could include these variables comparing Environmental Dynamism variability in others countries. Despite these limitations, this study represents an enhancement in emergent technologies studies in marketing.

\section{REFERENCES}

Barrales-Molina, V., Martínez-López, F. J., \& Gázquez-Abad, J. C. (2014). Dynamic Marketing capabilities: Toward an integrative framework. International Journal of Management Reviews, 16(4), 397-416. 
Boulding, W., Staelin, R., Ehret, M., \& Johnston, W. J. (2005). A Customer Relationship Management Roadmap: What Is Known, Potential Pitfalls, and Where to Go. Journal of Marketing, 69(4), 155-166.

Braganza, A., Brooks, L., Nepelski, D., Ali, M., \& Moro, R. (2017). Resource management in big data initiatives: Processes and dynamic capabilities. Journal of Business Research, 70, 328-337.

Chang, W., Park, J. E., \& Chaiy, S. (2010). How does CRM technology transform into organizational performance? A mediating role of Marketing capability. Journal of Business Research, 63(8), 849-855.

Chen, I. J., \& Popovich, K. (2003). Understanding customer relationship management (CRM). Business Process Management Journal, 9(5), 672-688.

Chuang, S. H., \& Lin, H. N. (2013). The roles of infrastructure capability and customer orientation in enhancing customer-information quality in CRM systems: Empirical evidence from Taiwan. International Journal of Information Management, 33(2), 271-281.

Chuang, S. H., \& Lin, H. N. (2017). Performance implications of information-value offering in e-service systems: Examining the resource-based perspective and innovation strategy. Journal of Strategic Information Systems, 26(1), 22-38.

Cooke, A. D. J., \& Zubcsek, P. P. (2017). The Connected Consumer: Connected Devices and the Evolution of Customer Intelligence. Journal of the Association for Consumer Research, 2(2), 164-178.

Davenport, T. H. (2006). Competing on analytics. Harvard Business Review, 84(1), 98-107, 134.

Day, G. S. (2011). Closing the Marketing Capabilities Gap. Journal of Marketing, 75(4), 183-195.

Faul, F., Erdfelder, E., Lang, A. G., \& Buchner, A. (2007). G* Power 3: A flexible statistical power analysis program for the social, behavioral, and biomedical sciences. Behavior Research Methods, 39(2), 175-191.

Felipe, C. M., Roldán, J. L., \& Leal-Rodríguez, A. L. (2016). An explanatory and predictive model for organizational agility. Journal of Business Research, 69(10), 4624-4631.

Germann, F., Lilien, G. L., Fiedler, L., \& Kraus, M. (2014). Do Retailers Benefit from Deploying Customer Analytics? Journal of Retailing, 90(4), 587-593.

Gorla, N., Somers, T. M., \& Wong, B. (2010). Organizational impact of system quality, information quality, and service quality. Journal of Strategic Information Systems, 19(3), 207-228.

Hair, J. F., Black, B., Babin, B., Anderson, R. E., \& Tatham, R. L. (2009). Análise multivariada de dados (6th ed.). Porto Alegre: Bookman.

Hair, J. F., Hult, G. T. M., Ringle, C. M., \& Sarstedt, M. (2017). A Primer on Partial Least Squares Structural Equation Modeling (PLS-SEM). Thousand Oaks: Sage.

Hair, J. F., Ringle, C. M., \& Sarstedt, M. (2011). PLS-SEM: Indeed a Silver Bullet. Journal of Marketing Theory and Practice, 19(2), 139-152.

Hayes, A. (2013). Introduction to mediation, moderation, and conditional process analysis. New York, NY: The Guilford Press.

Jaworski, B. J., \& Kohli, A. K. (1993). Market Orientation: Antecedents and Consequences. Journal of Marketing, 57(3), 53-70.

Jayachandran, S., Sharma, S., Kaufman, P., \& Raman, P. (2005). The Role of Relational Information Processes and Technology Use in Customer Relationship Management. Journal of Marketing, 69(4), 177-192.

Kim, G., Shin, B., \& Kwon, O. (2012). Investigating the Value of Sociomaterialism in Conceptualizing IT Capability of a Firm. Journal of Management Information Systems, 29(3), 327-362.

Kohli, A. K., \& Jaworski, B. J. (1990). Market Orientation: The Construct, Research Propositions, and Managerial Implications. Journal of Marketing, 54(April), 1-18.

Kozlenkova, I. V., Samaha, S. A., \& Palmatier, R. W. (2014). Resource-based theory in Marketing. Journal of the Academy of Marketing Science, 42(1), 1-21.

Lee, I., \& Lee, K. (2015). The Internet of Things (IoT): Applications, investments, and challenges for enterprises. Business Horizons, 58(4), 431-440.

MacKenzie, S.B., Podsakoff, P. M., \& Podsakoff, N. P. (2011). Construct Measurement and Validation Procedures in MIS and Behavioral Research: Integrating New and Existing Techniques. MIS Quarterly, 35(2), 293-334.

Matitz, Q. R. S., \& Bulgacov, S. (2011). O conceito desempenho em estudos organizacionais e estratégia: um modelo de análise multidimensional. Revista de Administração Contemporânea, 15(4), 580-607. 
BBR

16,4

Morgan, N. A. (2012). Marketing and business performance. Journal of the Academy of Marketing Science, 40(1), 102-119.

Morgan, N. A., Vorhies, D. W., \& Mason, C. H. (2009). Market orientation, Marketing capabilities, and firm performance. Strategic Management Journal, 30(8), 909-920.

Narver, J. C., \& Slater, S. F. (1990). The Effect of a Market Orientation on Business Profitability. Journal of Marketing, 54(4), 20-35.

Pavlou, P. A., \& Sawy, O. A. E. (2010). The "third hand": IT-enabled competitive advantage in turbulence through improvisational capabilities. Information Systems Research, 21(3), 443-471.

Pavlou, P. A., \& Sawy, O. A. (2013). Searching for a Simple Model of Dynamic Capabilities. SSRN Electronic Journal. https://doi.org/http://dx.doi.org/10.2139/ssrn.2369378

Persson, A., \& Ryals, L. (2014). Making customer relationship decisions: Analytics v rules of thumb. Journal of Business Research, 67(8), 1725-1732.

Podsakoff, P. M., MacKenzie, S. B., Lee, J. Y., \& Podsakoff, N. P. (2003). Common method biases in behavioral research: A critical review of the literature and recommended remedies. Journal of Applied Psychology, 88(5), 879-903.

Popovič, A., Hackney, R., Coelho, P. S., \& Jaklič, J. (2012). Towards business intelligence systems success: Effects of maturity and culture on analytical decision making. Decision Support Systems, 54(1), 729-739.

Popovič, A., Hackney, R., Coelho, P. S., \& Jaklič, J. (2014). How information-sharing values influence the use of information systems: An investigation in the business intelligence systems context. The Journal of Strategic Information Systems, 23, 270-283.

Provost, F., \& Fawcett, T. (2013). Data science for business: What you need to know about data mining and data-analytic thinking. Sebastopol: O’Reilly Media, Inc.

Rapp, A., Trainor, K. J., \& Agnihotri, R. (2010). Performance implications of customer-linking capabilities: Examining the complementary role of customer orientation and CRM technology. Journal of Business Research, 63(11), 1229-1236.

Singhal, K., \& Singhal, J. (2012). Opportunities for developing the science of operations and supply-chain management. Journal of Operations Management, 30(3), 245-252.

Song, M., Benedetto, C. A., \& Nason, R. W. (2007). Capabilities and financial performance: The moderating effect of strategic type. Journal of the Academy of Marketing Science, 35(1), 18-34.

Takahashi, A. R. W., Bulgacov, S., Semprebon, E., \& Giacomini, M. M. (2017). Dynamic capabilities, Marketing Capability and Organizational Performance. Brazilian Business Review, 14(5), 466-478.

Trainor, K. J. (2012). Relating Social Media Technologies to Performance: A Capabilities-Based Perspective. Journal of Personal Selling and Sales Management, 32(3), 317-331.

Trainor, K. J., Andzulis, J., Rapp, A., \& Agnihotri, R. (2014). Social media technology usage and customer relationship performance: A capabilities-based examination of social CRM. Journal of Business Research, 67(6), 1201-1208.

Tseng, S. M., \& Lee, P. S. (2014). The effect of knowledge management capability and dynamic capability on organizational performance. Journal of Enterprise Information Management, 27(2), 158-179.

Wade, M., \& Hulland, J. (2004). The Resource-Based View and Information Systems Research: Review, Extension, and Suggestions for Future Research1. MIS Quarterly, 28(1), 107-142.

Wamba, S. F., Gunasekaran, A., Akter, S., Ren, S. J., Dubey, R., \& Childe, S. J. (2017). Big data Analytics and firm performance: Effects of dynamic capabilities. Journal of Business Research, 70, 356-365.

Wang, Y., \& Hajli, N. (2017). Exploring the path to big data Analytics success in healthcare. Journal of Business Research, 70, 287-299.

Wedel, M., \& Kannan, P. K. (2016). Marketing Analytics for Data-Rich Environments. Journal of Marketing, $80(6), 97-121$. 
Xu, Z., Frankwick, G. L., \& Ramirez, E. (2016). Effects of big data Analytics and traditional Marketing Analytics on new product success: A knowledge fusion perspective. Journal of Business Research, 69(5), 1562-1566. 